\section{Avaliação do Estado Nutricional de Adultos e Idosos e Situação Nutricional da População Brasileiva}

\section{RESUMO}

As alterações do estado nutricional (desnutrição e obesidade) são relacionadas com sérios agravos para a saúde. O presente trabalho de revisão da literatura tem por objetivo descrever os principais métodos de avaliação do estado nutricional, com finalidade de facilitar o diagnóstico dos problemas nutricionais e acompanhar intervenções dietoterápicas. Descreve o método clínico, detalha aspectos da antropometria e os exames laboratoriais utilizados em avaliação do estado nutricional. Relaciona alguns dos principais índices múltiplos, utilizados tanto com fins diagnósticos e prognósticos. Informa a respeito da impedância bioelétrica, completando abordagem sobre os métodos convencionais, além de descrever as principais vantagens e desvantagens dos métodos não-convencionais. Finaliza com revisão sobre a situação nutricional da população brasileira, através da análise de dados obtidos em três inquéritos populacionais (1974, 1989, 1997). (Arq Bras Endocrinol Metab 2004;48/3:345-361)

Descritores: Avaliação nutricional; Estado nutricional; Desordens nutricionais; Adulto; Idoso; Inquéritos populacionais

\begin{abstract}
Nutritional Assessment of Adults and Elderly and the Nutritional Status of the Brazilian Population.

Nutritional disorders (undernutrition and obesity) are associated to increases in morbidity and mortality. This paper consists on a review of literature with the purpose of describing the main methods of nutritional assessment, in order to facilitate the diagnosis of nutritional disorders and the follow-up of dietetics interventions. It describes the clinical method, details procedures of anthropometry and laboratory evaluation and enrolls some of the multiple indices used for diagnosis and prognosis. Information about bioelectric impedance is given. Some aspects of non-conventional methods are reminded. Nutritional status of the Brazilian population is discussed, using the analysis of data collected from three populational surveys (1974, 1989, and 1997). (Arq Bras Endocrinol Metab 2004;48/3:345-361)
\end{abstract}

Keywords: Nutritional assessment; Nutritional status; Nutritional disorders; Adult; Elderly; Population Surveys

$\mathrm{O}$ ESTADO NUTRICIONAL EXPRESSA o grau no qual as necessidades fisiológicas por nutrientes estão sendo alcançadas (1), para manter a composição e funções adequadas do organismo (2), resultando do equilíbrio entre ingestão e necessidade de nutrientes (1). As alterações do estado nutricional contribuem para aumento da morbi-mortalidade. Assim sendo, a desnutrição predispõe a uma série de complicações graves, incluindo tendência à infecção, deficiência de cicatrização de feridas, falência respi- revisão

\author{
Kátia Acuña \\ Thomaz Cruz
}

\author{
Faculdade de Medicina da \\ Universidade Federal da Babia, \\ Salvador, $B A$.
}


ratória (3), insuficiência cardíaca, diminuição da síntese de proteínas a nível hepático com produção de metabólitos anormais, diminuição da filtração glomerular e da produção de suco gástrico (4).

Por outro lado, o sobrepeso e a obesidade são fatores de risco para variado número de agravos à saúde, dos quais os mais freqüentes são doença isquêmica do coração, hipertensão arterial, acidente vascular cerebral, diabetes mellitus tipo 2, colelitíase, osteoartrite (especialmente de joelhos), neoplasia maligna de mama pósmenopausa e de endométrio, esofagite de refluxo, hérnia de hiato e problemas psicológicos $(5,6)$.

\section{AVALIAÇĀO DO ESTADO NUTRICIONAL}

Os objetivos da avaliação do estado nutricional são: a) identificar os pacientes com risco aumentado de apresentar complicações associadas ao estado nutricional $(\mathrm{CAN})$, para que possam receber terapia nutricional adequada $(1,7-9)$; b) monitorizar a eficácia da intervenção dietoterápica $(1,9)$.

Esta avaliação pode ser feita através de métodos convencionais e não-convencionais (9). São métodos convencionais aqueles tradicionalmente usados, por sua consolidada utilização tanto na prática clínica quanto em estudos epidemiológicos. Têm como características principais: a) praticidade; b) custo aceitável; c) refletem com certa precisão o estado nutricional do indivíduo (9). Os métodos não-convencionais são aqueles que apresentam limitações no seu uso, como equipamentos de custo elevado, dificuldades técnicas para sua execução, entre outras, que impossibilitam seu uso de forma rotineira. Geralmente são métodos mais sensíveis, utilizados como referência em pesquisas (9).

\section{Métodos Convencionais}

Nesta categoria, encontra-se um largo espectro de procedimentos, incluindo (7-9):

História clínica (1,10-12);

Exame físico para detectar deficiências nutricionais específicas $(1,10,11,13)$;

Antropometria: peso; altura; combinações de altura e peso; medidas de dobras ou pregas cutâneas; circunferências; comprimento de segmentos; largura óssea; compleição $(5,10,13-16)$;

Exames laboratoriais: hematócrito, hemoglobina, linfócitos totais, proteínas séricas (albumina, préalbumina; transferrina), índice creatinina-altura, colesterol sérico, balanço nitrogenado $(7,8,10,17)$;

$(7,17,18)$

Índices múltiplos: diversos índices prognósticos

Impedância bioelétrica $(19,20)$.

\section{História Clínica}

Em toda prática clínica, obter a anamnese tem um papel fundamental. Do ponto de vista nutricional, aspectos relevantes são:

Perda de peso: trata-se, provavelmente, da variável mais freqüentemente avaliada (7). Perda de peso acima de $10 \%$ é significativa $(8,12)$. Outro fator que deve ser investigado é a maneira como a perda ocorreu, se contínua ou com recuperações, avaliando a situação nas duas últimas semanas $(12,21)$;

Alterações do padrão alimentar: devem ser avaliadas quanto à duração (em semanas) e o tipo (quantitativa e qualitativa) (12). Neste caso, procura-se detectar a presença de disfagia ou alterações do estado mental (1);

Presença de sintomas gastrointestinais: anorexia, náusea, vômitos e diarréia (pelo menos três evacuações líquidas por dia) são considerados importantes quando estão presentes de forma contínua por mais de 15 dias $(12,21)$;

Avaliação da capacidade funcional: está relacionada com alterações de atividades físicas habituais do paciente, podendo obrigá-lo desde a interrupção das atividades cotidianas até grau extremo de inatividade, onde o paciente permanece acamado a maior parte do tempo $(12,21)$;

Demanda metabólica: procura-se investigar situações que causam aumento de requerimentos nutricionais, como infecções, trauma, queimaduras, fraturas, sepsis, gravidez, lactação $(10,21)$;

Antecedentes médicos: cirurgias prévias com localização de ressecções intestinais, doenças crônicas e suas complicações $(1,10,11)$;

Uso de medicamentos: pode afetar o estado nutricional de várias formas: a) diminuindo o apetite: furosemida, hidroclotiazida, digitálicos etc.; b) alterando ou diminuindo o paladar: AAS, anfetaminas etc.; c) aumentando o apetite: anti-histamínicos, drogas psicotrópicas, corticosteróides (22); d) alterando a absorção de nutrientes (e.g. o uso de anticoncepcionais orais interfere na absorção de folato) $(9,10)$;

História social: nela há aspectos importantes a serem investigados, pois podem influenciar a compreensão sobre a doença e incluem fatores de risco que podem afetar a aderência ao tratamento: a) ocupação; b) escolaridade; c) condições de habitação; d) nível socioecômico; e) uso de substâncias, como álcool, tabaco, drogas ilícitas e cafeína $(1,11)$;

História dietética: refere-se a uma revisão dos padrões usuais de ingestão de alimentos utilizando técnicas especiais, sendo a mais conhecida o recordatório alimentar de 24 horas (método qualitativo que investiga tudo o que o paciente ingeriu nas últimas 24 horas) $(1,11)$. 


\section{EXAME Físico}

O exame físico direcionado para detectar deficiências nutricionais deve ser minucioso, com o objetivo de identificar sinais de carências específicas de nutrientes.

A inspeção geral proporciona muitas informações úteis, como: a) sinais de depleção nutricional: perda de tecido subcutâneo na face, tríceps, coxas e cintura; b) perda de massa muscular nos músculos quadríceps e deltóide, lembrando que repouso prolongado leva a atrofia muscular; c) presença de edema em membros inferiores, região sacral e ascite; d) coloração de mucosas: palidez da anemia $(1,10,11,13)$.

Cabe lembrar que Detsky e cols. (23) propuseram um modelo de questionário-padrão que investigava aspectos da história clínica e de exame físico, denominado Avaliação Subjetiva Global (ASG). A ASG permite a classificação em três categorias: $\mathrm{A}=\mathrm{Bem}$ nutrido; $\mathrm{B}=$ Moderadamente (ou suspeito de ser) desnutrido; e $\mathrm{C}=$ Gravemente desnutrido (tabela 1). A partir de então, a ASG tem sido extensamente estudada na literatura, sendo validada ao se a comparar com outros métodos (24) e modificada para atender a situações clínicas diversas, como as de pacientes com nefropatia, neoplasia, hepatopatia, HIV positivos e geriátricos (25).

\section{ANTROPOMETRIA}

A antropometria é uma técnica desenvolvida por antropologistas no final do século XIX, usando medidas simples para quantificar diferenças na forma humana $(26,27)$, porém a era moderna da antropometria nutricional se iniciou durante a primeira guerra mundial com a preocupação com a eficiência física dos soldados (27).

Antropometria é o método não-invasivo de baixo custo e universalmente aplicável, disponível para avaliar o tamanho, proporções e composição do corpo humano (5).

A idade deve ser estabelecida, pois tanto as medidas recomendadas quanto os padrões de referência são considerados com base na mesma $(5,11)$. Outro fator que deve ser considerado é o gênero, pois existem diferenças expressivas entre o tamanho de homens e mulheres (5).

A antropometria permite a obtenção de muitas informações, porém peso, altura, suas combinações e pregas cutâneas são os métodos antropométricos mais utilizados em estudos epidemiológicos (15).

\section{Altura}

A altura representa o maior indicador do tamanho corporal geral e do comprimento dos ossos (14). Adultos são geralmente medidos em pé (28). Quando a estatura não pode ser medida por dificuldade de permanecer em pé ou problemas sérios de coluna, no adulto jovem a envergadura dos braços é equivalente à altura $(13,14)$. Outra possibilidade é a utilização da medida altura do joelho (28). A altura é então estimada utilizando fórmulas (13): homem $(\mathrm{cm})=64,19-(0,04 \times$ idade $)+$ $(0,02 \times$ altura do joelho em $\mathrm{cm})$; mulher $(\mathrm{cm})=84,88$ $-(0,24 \times$ idade $)+(1,83 \times$ altura do joelho $\mathrm{em} \mathrm{cm})$.

\section{Peso}

$\mathrm{O}$ peso corresponde à soma de todos os componentes de cada nível da composição corporal. É uma medida aproximada das reservas totais de energia do corpo, e mudanças no peso refletem alterações no equilíbrio entre ingestão e consumo de nutrientes (13).

Três considerações sobre o peso são importantes:

Porcentagem de alteração de peso (\%AP): é estabelecido comparado o peso usual (PU), que é aquele que o indivíduo usualmente apresenta quando está saudável, com o peso atual (PA), medido no momento da avaliação, utilizando a fórmula (12): \%AP $=(\mathrm{PA}-\mathrm{PH}) / \mathrm{PH} \times 100$;

Peso ideal (PI): é padrão de referência para faixa etária e gênero, sendo o americano obtido através do National Health and Nutrition Examination Survey (NHANES I 1971-1974; NHANES II 1976-1980) realizados pelo National Center of Health Statistics, NCHS. A OMS preconizou utilizar as Tabelas de Crescimento do NCHS (28). Anjos (29) critica a utilização de tabelas de peso ideal, considerando a grande variação da estatura média das populações adultas do mundo;

Porcentagem do peso corporal ideal (PCI\%): é calculado através da fórmula: PA/PI x 100. Albert \& Callaway (10) consideraram $80 \%$ do PCI\% como altamente indicativo de desnutrição; já Starlings \& Hark (11) consideraram PCI\% abaixo de 70\% como desnutrição grave e acima de $120 \%$ como obesidade; Waitzberg (30) considerou redução moderada entre $6 \mathrm{l}$ a $80 \%$ e grave $\leq 60 \%$.

\section{Combinações peso e altura}

Peso e altura representam as variáveis antropométricas mais comumente disponíveis em estudos epidemiológicos (15). As suas combinações medem peso corporal corrigido pela altura (15), porém não conseguem distinguir adiposidade de massa muscular e edema (28).

Por isto, no adulto temos as seguintes combinações:

Peso-altura: para determinar se o peso de um adulto é apropriado para a altura, precisa ser compara- 
Tabela 1. Componentes da Avaliação Subjetiva Global (ASG)

(Selecione a categoria apropriada com (X), ou escreva o valor numérico nos lugares indicados por \#)

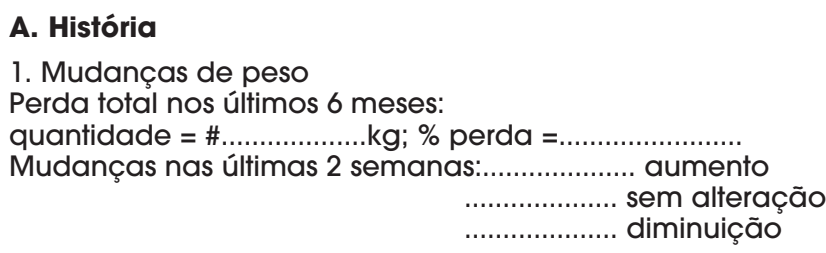

2. Modificações na ingestão alimentar (em relação com o normal):

3. Sintomas gastrointestinais (que persistem por mais de 2 semanas): nenhum; náusea; vômitos: diarréia; anorexia

4. Capacidade funcional:

sem disfunção (e.g. capacidade total) disfunção

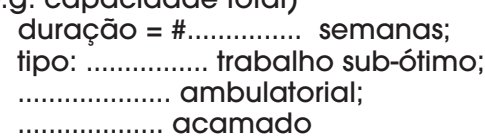

5. Doença e demanda metabólica:

Diagnóstico principal (especificar): Demanda metabólica (stress): sem stress; baixo stress; stress moderado; alto stress

B. Exame físico (em cada item especificar: $0=$ normal, $1+=$ leve, $2+=$ moderado, $3+=$ grave)

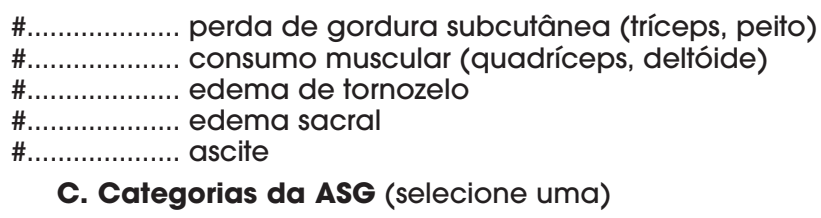

Fonte: referência 23.

do com padrões de referência. Os mais comuns são as tabelas do Metropolitan Life Insurance, que distribuem o peso ideal pela altura, considerando o gênero e a compleição $(1,28)$;

Índice de massa corporal ou corpórea (IMC): foi criado por Quetelet (15), sendo, por isso, também denominado de índice de Quetelet (28). Sua utilização na prática clínica foi proposta há três décadas $(28)$. É considerado por diversos autores o melhor indicador de massa corporal no adulto (28), porém outros autores $(13,29)$ chamam atenção para três limitações do IMC: 1) relação com a proporcionalidade do corpo, pessoas com as pernas curtas para a sua altura terão IMC aumentado; 2) relação com a massa livre de gordura, especialmente em homens, pois atletas e indivíduos musculosos podem ter IMC na faixa da obesidade; 3 ) relação com a estatura, que, apesar de baixa, pode ser significativa, especialmente em menores de 15 anos $(13,16,28)$. Em 1995, um Comitê de Espe- cialistas da OMS modificou os pontos de corte do IMC (31) para emagrecimento (5) e, em 1998, para obesidade (6), preconizando sua utilização tanto para diagnóstico de desnutrição $(4,5)$ quanto de obesidade (6), sendo os seguintes: magreza grau III (grave): IMC < 16,0; magreza grau II (moderada): 16,0 $\leq$ IMC $\leq 16,99$; magreza grau I (leve): $17,0 \leq$ IMC $\leq$ 18,49 ; faixa normal: $18,5 \leq$ IMC $\leq 24,99$; pré-obesidade (aumentado): 25,0 $\leq$ IMC $\leq 29,99$; obesidade grau I (moderado): $30,00 \leq \mathrm{IMC} \leq 34,99$; obesidade grau II (grave): $35,0 \leq \mathrm{IMC} \leq 39,99$; obesidade grau III (muito grave): IMC $\geq 40,00$. Anjos (29) sugeriu, ainda, que, apesar de o IMC não indicar a composição corporal, a facilidade de sua mensuração e sua relação com morbi-mortalidade parecem ser motivos suficientes para sua utilização como indicador do estado nutricional em estudos epidemiológicos em associação ou não com outras medidas antropométricas. A curva de morbi-mortalidade tem sido identificada como um 
"U", assimétrico, com o menor risco na parte horizontal com IMC de 20 a $30 \mathrm{~kg} / \mathrm{m}^{2}$. Os dois extremos do IMC estão associados com maior risco de morbimortalidade, porém de causas de morte diferentes (29). O IMC baixo está associado com morte por tuberculose, câncer pulmonar e doença pulmonar obstrutiva crônica (29), sendo que o IMC $=12 \mathrm{~kg} / \mathrm{m}^{2}$ é considerado limite mínimo para sobrevivência humana (29). O IMC alto, com morte por doenças cardiovasculares, diabetes e, para homens, câncer de cólon (29). Pode ser calculado utilizando a fórmula: IMC $=$ peso $(\mathrm{kg}) /$ altura $(\mathrm{m})^{2}(5)$ ou através do normograma proposto por Bray (16). Quanto à eficiência do IMC no diagnóstico de obesidade, observa-se controvérsia na literatura. Desta forma, Garrow \& Webster (36) concluíram que o IMC pode ser considerado conveniente e de fácil execução no diagnóstico de obesidade. Porém Smalley e cols. (37), considerando a grande variação individual da gordura corporal determinada pelo IMC e a estimada por densitometria, sugeriram o uso cauteloso do IMC como indicador de obesidade. Recentemente, Acuña e cols. (38), ao estudar o estado nutricional de pacientes hospitalizados, encontraram uma concordância fraca entre IMC e o Índice Sugestivo de Desnutrição (ISD) proposto por Waitzberg (30), e concluem que o Índice de Massa Corporal não é um bom parâmetro para avaliar o estado nutricional de adultos hospitalizados, sendo um indicador de proporções corporais. Esclarecendo melhor, uma pessoa magra pode estar bem nutrida e uma pessoa obesa pode estar desnutrida.

\section{Circunferências}

À medida em que se torna necessário avaliar de forma mais completa a composição corporal, dados antropométricos adicionais devem ser obtidos (1). As circunferências são afetadas pela massa gorda, massa muscular e tamanho ósseo (16). É possível medir uma grande variedade de circunferências corporais (14), porém as principais circunferências utilizadas na prática clínica são (1):

Circunferência do braço (CB): é muito utilizada, pois a sua combinação com a medida da prega cutânea do tríceps (PCT) permite, através da aplicação de fórmulas, calcular a circunferência muscular do braço $(\mathrm{CMB})$ e a área muscular do braço (AMA), área de músculo sem osso (1), que são correlacionadas com a massa muscular total, sendo utilizadas para diagnosticar alterações da massa muscular corporal total e, assim, o estado nutricional protéico $(1,5,13,14,16,28)$;

Circunferência da cintura: sua medida não deve ser feita sobre roupas, o sujeito permanece em pé, com os pés juntos, os braços estendidos lateralmente e o abdome relaxado (14). A medida deve ser tomada em plano horizontal com fita inelástica no ponto mais estreito do tronco (14). É indicador de adiposidade profunda (14);

Circunferência do quadril: deve ser medida com paciente trajando roupas leves e soltas, em pé, com os braços levantados para os lados e os pés juntos. $\mathrm{O}$ examinador senta ao lado do sujeito para melhor visualizar o nível da extensão máxima dos glúteos, dispondo a fita antropométrica em plano horizontal, que deve ser estendida sobre a pele sem comprimir as partes moles (5);

Relação da cintura para o quadril (RCQ): é calculada dividindo a medida da circunferência da cintura $(\mathrm{cm})$ pela do quadril $(\mathrm{cm})(1,16)$. É fortemente associada à gordura visceral, sendo um índice aceitável de gordura intra-abdominal (16). É a medida de adiposidade mais freqüentemente utilizada, permitindo diferenciar a obesidade ginecóide e andróide (1). Uma RCQ de 1,0 ou mais para homens e de 0,8 ou mais para mulheres é indicativo de obesidade andróide e risco aumentado de doenças relacionadas com a obesidade (1);

Circunferência da panturrilha: fornece a medida mais sensível de medir massa muscular no idoso, sendo superior à circunferência do braço $(5)$;

Perímetro cefálico: muito utilizado para acompanhar o desenvolvimento de crianças menores de três $\operatorname{anos}(1)$.

\section{Pregas Cutâneas}

A gordura subcutânea corresponde a $50 \%$ da gordura armazenada do corpo, e pode refletir de maneira acurada o conteúdo de gordura corporal total, baseado no fato de que a espessura da gordura é relativamente constante $(7,18)$. A medida das pregas ou dobras cutâneas (PC) apresenta duas vantagens: 1) fornecer uma maneira relativamente simples e não-invasiva de estimar a gordura corporal; 2) caracterizar a distribuição da gordura subcutânea (14).

Uma grande variedade de PC pode ser medida $(14,16)$, porém as mais utilizadas na prática clínica são (28):

Prega cutânea do tríceps (PCT): a região do tríceps é o local mais freqüentemente utilizado, pois se considera que seja o mais representativo da camada subcutânea de gordura $(18,28)$. Pode ser comparada a padrões de referência com determinação do percentil (28). Os padrões mais comuns de comparação são os propostos por Jelliffe (4l), que são baseados em militares europeus e mulheres americanas de baixa renda, e por Frisancho (42), baseado nas medidas aferidas em 
homens e mulheres americanos brancos que participaram do National Health and Nutrition Survey (NHANES) 1971-1974. Porém, Thuluvath \& Triger (43) realizaram estudo comparando medidas de PCT e CMB em 125 pacientes com doença hepática crônica com as tabelas de Jelliffe e Frisancho, e demonstraram que ambas apresentam problemas de confiabilidade (21), de forma que os autores fazem a pergunta: How valid are our reference standards of nutrition? (Quão válidos são nossos padrões nutricionais de referência?) (43);

Somatório de pregas cutâneas: existem várias equações utilizando a soma de diversas combinações de PC, mas devem ser selecionadas baseadas na idade, gênero, etnia e nível de atividade física (16).

\section{Outras Medidas}

Outras medidas em antropometria não incluídas nos protocolos de medidas recomendadas pela OMS (5) consistem na medição de segmentos (e.g. envergadura do braço) e diâmetros ósseos $(14,16)$. A avaliação do tamanho do esqueleto é feita utilizando equipamentos apropriados denominados antropômetros ósseos e compassos de diferentes tamanhos $(14,16)$. Sua principal utilidade consiste em permitir a determinação da compleição física ou porte, que pode ser pequeno, médio e grande (15).

\section{EXAMES LABORATORIAIS}

Vários exames bioquímicos são as medidas mais objetivas do estado nutricional (1), usados para detectar deficiências subclínicas e para confirmação diagnóstica (28), com a vantagem de possibilitar seguimento de intervenções nutricionais ao longo do tempo (17).

Os exames laboratoriais de uso mais freqüente na prática clínica são descritos a seguir. Cabe lembrar que uma série de dosagens sangüíneas para estudar componentes nutricionais específicos, como minerais (e.g. cálcio), ferro, vitaminas, tem sua indicação específica, não sendo considerados como métodos convencionais $(17,28)$.

\section{Hematológicos}

Os parâmetros hematológicos mais utilizados em avaliação nutricional são hematócrito (HT), hemoglobina (HG) e linfócitos totais (LINF) (17).

Os valores de hematócrito e hemoglobina são dependentes da idade e gênero (28).

A contagem total de linfócitos (CTL) expressa condições imunológicas e também os valores normais variam conforme o autor. Para Weinsier e cols. (44), a normalidade compreende valores iguais ou maiores que $1.500 / \mathrm{mm}^{3}$, depleção moderada de $1.200 \mathrm{a}$ $1.500 / \mathrm{mm}^{3}$ e grave abaixo de $1.200 / \mathrm{mm}^{3}$. Segundo Seltzer e cols. (45), o risco maior de complicações associadas com estado nutricional ocorre quando a CLT for inferior a $1.500 / \mathrm{mm}^{3}$, concordando com os valores preconizados pela FELANPE (46). Bottoni e cols. (17) consideraram os seguintes valores: a) depleção leve: 1.200 a $2.000 / \mathrm{mm}^{3}$; b) depleção moderada: 800 a $1.199 / \mathrm{mm}^{3}$; c) depleção grave: < $800 / \mathrm{mm}^{3}$.

\section{Avaliação do Estado Protéico}

As proteínas são essenciais para as funções reguladoras (e.g. hormônios e enzimas) e estruturais (e.g. colágeno e elastina) (28).

As proteínas séricas mais freqüentemente avaliadas para determinação do estado nutricional são albumina, transferrina e pré-albumina (7).

\section{Albumina}

É a proteína mais abundante do plasma e dos líquidos extracelulares (17), sendo uma das mais extensamente estudadas, com aproximadamente 19.000 citações no Index Medicus nos últimos trinta anos (8).

Tem importância preponderante na determinação da pressão colóido-osmótica do plasma, exercendo função de proteína de transporte (cálcio, ácidos graxos de cadeia longa, medicamentos etc.) (17).

A concentração sérica de albumina depende de muitos fatores $(1,8,17,27)$ : a) síntese hepática: depende da função do hepatócito e da ingestão e absorção de substratos protéicos, encontrando-se diminuída no hipotireoidismo quando há níveis circulantes excessivos de cortisol durante estresse e em doença parenquimatosa hepática; b) perdas anormais de albumina: doença renal (síndrome nefrótica), eclâmpsia, enteropatia perdedora de proteína e queimaduras; c) catabolismo aumentado: estresse, hipermetabolismo, síndrome de Cushing e algumas neoplasias; d) trocas entre os compartimentos: alteradas em situações patológicas, com seqüestro para o extravascular (e.g. trauma, infecção); d) volume de distribuição: afetado pelo estado de hidratação.

Apesar da limitação decorrente da meia vida prolongada, interferindo na detecção de alterações agudas do estado nutricional, e de sofrer alterações por diversas outras razões não-nutricionais $(1,8,17,27)$, os níveis séricos de albumina são fortemente relacionados com aumentos na morbidade (tempo de internação prolongado, cicatrização deficiente de feridas) e da mortalidade (27). 
Por isso, é uma das variáveis mais freqüentemente utilizadas para compor índices prognósticos (17), sendo também considerada o melhor índice isolado de predição de complicações $(7,48)$.

Em relação aos valores da albumina, observa-se variação em relação à idade (28) e também aos valores preconizados por diferentes autores conforme apresentado na tabela 2 .

\section{Transferrina}

É uma beta globulina transportadora de ferro no plasma (7), sendo uma proteína de vida média intermediária (aproximadamente oito dias) entre a albumina e as proteínas de rápido turnover $(7,17)$.

Apesar do fato de que a vida média mais curta seja, teoricamente, uma vantagem sobre albumina, estudos clínicos não observaram diferenças significativas (7).

Por isto, alguns autores afirmam que sua medição habitual, sem finalidade de pesquisa, não apresenta vantagem sobre a dosagem da albumina (10) e outros já não incluem a transferrina na avaliação do estado protéico (8).

\section{Pré-albumina}

É uma proteína de transporte de hormônios tireoideanos que existe na circulação, formando um complexo com a proteína transportadora de retinol $(7,8,17)$. Tem uma vida média de 2 a 3 dias $(7,8,17)$, porém estudos não mostraram vantagem sobre a albumina (7), sendo considerada por outros autores como não confiável como índice de estado nutricional (8).

\section{Índice Creatinina-Altura}

Trata-se de método para avaliar a massa muscular cor- pórea baseando-se no fato de que $98 \%$ da creatinina está localizada nos músculos (17).

É calculado a partir da dosagem da creatinina na urina de 24 horas, a qual deve ser rigorosamente coletada, impossibilitando seu uso em pacientes com insuficiência renal ou em uso de diuréticos, como na falência cardíaca ou hepática $(8,17,49)$.

A dependência de uma coleta de urina acurada e completa, e a exigência de dieta desprovida de carne, podem dificultar a realização deste exame na prática clínica (49).

\section{Balanço Nitrogenado}

Permite monitorizar a adequação de terapia nutricional (17), avaliando o grau de equilíbrio entre a ingestão e a excreção urinária de nitrogênio $(7,17)$. Quando a ingestão é suficiente para cobrir as perdas, obtém-se um balanço positivo (e.g. fase anabólica sucessiva a um evento catabólico, crescimento, atletas). Se, ao contrário, as perdas superam as introduções, verifica-se balanço negativo (e.g. trauma, sepse, queimaduras, fístulas etc.) (17). Pelas dificuldades técnicas, sua precisão somente se viabiliza em pacientes internados em unidades metabólicas (17).

\section{Colesterol Sérico}

A hipocolesterolemia (abaixo de $150 \mathrm{mg} / \mathrm{dl}$ ) tem sido estudada como índice prognóstico em desnutrição, com detecção de aumento da mortalidade e tempo de permanência hospitalar $(8,17)$. Níveis aumentados de colesterol são fator de risco para doença coronariana (28).

\section{Índices Múltiplos}

Vários índices com múltiplos parâmetros foram criados na literatura com o objetivo de aumentar a sensibili-

Tabela 2. Valores de nível sérico de albumina referidos por diferentes autores.

\begin{tabular}{|c|c|c|c|c|}
\hline \multirow[b]{2}{*}{ Autor } & \multicolumn{4}{|c|}{ Valores para albumina g/dl } \\
\hline & Depleção grave & Depleção moderada & Depleção leve & Normal \\
\hline Bistrian e cols. (50) & $<2,8$ & 2,8 a 3,4 & - & $\geq 3,5$ \\
\hline Bistrian e cols. (51) & $<2,8$ & 2,8 a 3,5 & - & $>3,5$ \\
\hline Weinsier e cols. (44) & $<2,8$ & 2,8 a 3,4 & - & $\geq 3,5$ \\
\hline Bistrian $(52,53)$ & Risco nutricional aumentado $>3,0$ & & & \\
\hline Blackburn e cols. (54) & $<2,1$ & 2,1 a 3,0 & - & \\
\hline Mullen e cols. (55) & Risco nutricional aumentado $>3,0$ & & & \\
\hline Willard e cols. (56) & Risco nutricional aumentado $>3,4$ & & & \\
\hline Harvey e cols. (48) & Risco nutricional aumentado $>2,2$ & & & \\
\hline Detsky e cols. (57) & Risco nutricional aumentado $>3,0$ & & & \\
\hline Albert \& Callaway (10) & Risco nutricional aumentado $>3,5$ & & & \\
\hline Smith \& Mullen (7) & $<2,2$ & 2,2 a 2,7 & 2,8 a 3,5 & $>3,5$ \\
\hline Gibson (28) & $<2,8$ & 2,8 a 3,4 & & $\geq 3,5$ \\
\hline Klein e cols. (46) & $>2,2=$ possível kwashiorkor & 2,8 a $3,5=$ comprometido & & \\
\hline Coppini e cols. (24) & Risco nutricional aumentado $>3,5$ & & & \\
\hline Bottoni e cols. (17) & $<2,4$ & 2,4 a 2,9 & 3,0 a 3,5 & $>3,5$ \\
\hline
\end{tabular}

Fonte: referência 60 . 
dade e especificidade no diagnóstico de alterações do estado nutricional (7). São conhecidos como índices prognósticos pela capacidade de tentar prever as complicações associadas à nutrição, porém podem também ser usados como instrumentos diagnósticos $(7,17,18)$. Os mais conhecidos são $(7,17,18,47)$ :

Índice prognóstico nutricional (PNI): proposto pelo grupo de Mullen da Universidade da Pensilvânia (58). Utilizaram a seguinte fórmula: PNI $(\%$ risco $)=$ 158 - $(16,6 \times \mathrm{ALB})-(0,78 \times \mathrm{PCT})-(0,2 \times \mathrm{TRS})-$ $(5,8 \times \mathrm{DCH})$; onde: $\mathrm{ALB}=$ albumina sérica $(\mathrm{g} / \mathrm{dl})$; PCT $=$ prega cutânea do tríceps em mm; TRS $=$ transferrina sérica $(\mathrm{mg} / \mathrm{dl}) ; \mathrm{DCH}=$ hipersensibilidade cutânea retardada $(0=$ reatividade nula; $1=$ diâmetro do ponto $<5 \mathrm{~mm} ; 2=$ diâmetro do ponto $\geq 5 \mathrm{~mm}$ ). São considerados de baixo risco os pacientes com PNI $<40 \%$; de risco intermediário aqueles com PNI entre $40 \%$ e $50 \%$, e de alto risco os que apresentem PNI $>50 \%$. A crítica a este índice está em utilizar dois parâmetros que não são independentes um do outro (ALB e TRS) (17);

Índice prognóstico hospitalar (HPI): proposto pelo grupo de Blackburn e cols. (48), utilizando a seguinte fórmula: $\mathrm{HPI}=(0,91 \times \mathrm{ALB})-(1 \times \mathrm{DCH})-$ $(1,44 \times$ SEP $)+(0,98 \times$ Dx $)-1,09$; onde: $\mathrm{DCH}=$ hipersensibilidade cutânea retardada (grau $\mathrm{l}=$ resposta positiva a um ou mais antígenos; grau 2 = resposta negativa a todos os antígenos); SEP $=$ sepse $(1=$ presente; $2=$ ausente); Dx = diagnóstico ( 1 = presença de neoplasia; 2 = ausência de neoplasia);
Avaliação nutricional instantânea (INA): proposta por Seltzer e cols. (45) ao avaliar retrospectivamente 500 internações consecutivas. Utiliza a dosagem de albumina $<3,5 \mathrm{~g} / \mathrm{dl}$ e o número de linfócitos totais $<1.500 \mathrm{~mm}^{3}$;

Índice sugestivo de desnutrição (ISD): proposto por Waitzberg (30), visando a obtenção de índice de fácil utilização na prática clínica, combinando variáveis laboratoriais e antropométricas. O ISD é calculado pela somatória dos valores ponderais conferidos a sete parâmetros nutricionais aferidos, considerando-se como desnutrido o paciente cujo resultado da somatória for igual ou maior que três (17). As variáveis utilizadas e respectivos pontos de corte são apresentados na tabela 3 ;

Índice de Risco Nutricional (IRN): proposto por Buzby e cols. (58). No seu cálculo utilizaram a seguinte equação: $\operatorname{IRN}=(1,489 \mathrm{x}$ albumina sérica, $\mathrm{g} / \mathrm{l})+4 \mathrm{l}, 7 \mathrm{x}$ (peso atual/peso usual). Permite a seguinte classificação: a) não-desnutrido, IRN > 100; b) desnutrição leve, IRN de 97,5 a 100; c) desnutrição moderada, IRN de 83,5 a 97,$4 ;$ d) desnutrição grave, IRN abaixo de 83,5 . O peso usual foi definido como o peso estável seis meses antes da admissão hospitalar (61).

Vários autores enfatizam a ausência de padrãoouro para diagnóstico de desnutrição $(2,21,31$, $43,53,57,60)$. Smith \& Mullen (7) opinam que o melhor método é a maneira organizada de abordagem multifatorial, utilizando os seguintes critérios: história,

Tabela 3. Variáveis utilizadas para cálculo do Índice Sugestivo de Desnutrição (ISD) proposto por Waitzberg com respectivas pontuações e pontos de corte.

\begin{tabular}{|c|c|c|}
\hline \multirow[b]{2}{*}{$\begin{array}{l}\text { VARIÁVEL } \\
\text { (FÓRMULA) }\end{array}$} & \multicolumn{2}{|c|}{ PONTOS DE CORTE E PONTUAÇĀO } \\
\hline & $\begin{array}{l}\text { MODERADAMENTE } \\
\text { REDUZIDO }\end{array}$ & $\begin{array}{l}\text { GRAVEMENTE } \\
\text { REDUZIDO }\end{array}$ \\
\hline 1. \% PERDA DE PESO (PP) & 10 a $20 \%$ & maior que $20 \%$ \\
\hline$\% \mathrm{PP}=(\mathrm{PA}-\mathrm{PH}) / \mathrm{PH} \times 100$ & 1 & 2 \\
\hline 2. \% PESO CORPORAL IDEAL & 61 a $80 \%$ & maior ou igual a $60 \%$ \\
\hline (peso atual/peso ideal x 100) & 1 & 2 \\
\hline 3. \% PREGA CUTNEA DO TRÍCEPS & 61 a $80 \%$ & maior ou igual a $60 \%$ \\
\hline (PCT medida/PCT padrão x 100) & 1 & 2 \\
\hline 4. \% CIRCUNFERÊNCIA MUSCULAR DO & 61 a $80 \%$ & maior ou igual a $60 \%$ \\
\hline BRAÇO & 1 & 2 \\
\hline (CMB medida/CMB padrão x 100) & 2,4 a $2,9 \mathrm{mg} / \mathrm{dl}$ & menor de $2,4 \mathrm{mg} / \mathrm{dl}$ \\
\hline 5. ALBUMINA & $\begin{array}{c}2 \\
800 \text { a } 1199 / \mathrm{mm}^{3}\end{array}$ & menor que $800 / \mathrm{mm}^{3}$ \\
\hline 6. LINFÓcITOS & 1 & 2 \\
\hline 7. HEMATÓCRITO & 37 a 43 & menor que 37 \\
\hline Masculino & 31 a 37 & menor que 31 \\
\hline Feminino & 0 & 1 \\
\hline
\end{tabular}

PA = peso atual (medido no momento da avaliação); $\mathbf{P H}=$ peso habitual (que é aquele que o indivíduo usualmente apresenta quando está saudável); PCT = Prega cutânea do tríceps; CMB = Circunferência Muscular do Braço.

Fonte: referências 30,17 e 60 . 
exame físico, peso, CMB, PCT e proteínas séricas. Jeejeebhoy e cols. (2) afirmam que, quando o diagnóstico de desnutrição é feito pela presença de um único parâmetro, $22 \%$ da população normal poderia ser classificada como anormal e $80 \%$ dos pacientes hospitalizados seria erroneamente classificado como desnutridos. Afirmam que este diagnóstico deve se basear em pelo menos três critérios (2).

\section{Impedância Bioelétrica}

É um método rápido, não-invasivo e relativamente barato para avaliar a composição corporal (17). Este método utiliza a passagem de uma corrente elétrica de baixo nível através do corpo do paciente e a impedância $(\mathrm{Z})$, ou oposição ao fluxo da corrente, é medida $(16,20)$. Mede a massa magra (livre de gordura) pelas diferenças de condutibilidade elétrica, sendo considerada uma técnica ainda pouco utilizada, mas atrativa para uso em pacientes hospitalizados e inquéritos populacionais (18).

\section{Aspectos Peculiares do Idoso}

O idoso (60 ou mais anos) (5) apresenta peculiaridades relacionadas com o processo de envelhecimento, como: a) redução progressiva da altura, de um a dois cm por década; b) ganho progressivo de peso e IMC até em torno de 65 a 70 anos, diminuindo a partir de então; c) alterações da composição corporal, com redistribuição de gordura, que diminui a nível periférico e aumenta no interior do abdome, e redução da massa magra $(5,13,62)$. Alguns autores consideram que a desnutrição pode ser difícil de distinguir das alterações resultantes do processo natural do envelhecimento $(62,63)$, porém se não for detectada, pode resultar em agravamento de condições clínicas e aumento da mortalidade (62).

A população idosa é particularmente propensa a problemas nutricionais devido a fatores relacionados com as alterações fisiológicas e sociais, ocorrência de doença crônica, uso de várias medicações, problemas na alimentação (comprometendo a mastigação e deglutição), depressão e alterações da mobilidade com dependência funcional $(62,64,65)$.

Perda de peso involuntária, redução do apetite e caquexia são comuns na população geriátrica $(66,67)$. Anorexia é a principal causa de desnutrição no idoso, de etiologia multifatorial, que engloba doença sistêmica, iatrogenia e fatores psicossociais $(67,68)$. Os receptores gustativos e olfativos têm sua função diminuída com o envelhecimento, comprometendo a qualidade estimulante do apetite contida nos alimentos (68). Também se observa lentificação do esvaziamento gástrico, com o aumento da saciedade (estado que se segue a uma refeição no qual a fome encontra-se inibida) e da saciação (processo de regulação que ocorre durante a alimentação, que inibe a ingestão de mais alimento) (68). Estas alterações decorrentes do processo fisiológico de envelhecimento comprometem a ingestão de nutrientes, podendo levar à desnutrição (68).

Muitos pesquisadores, durante os últimos 25 anos do século passado, tentaram desenvolver instrumentos válidos para identificar os idosos desnutridos ou em risco aumentado de complicações relacionadas ao estado nutricional $(63,69)$, porém observa-se na literatura pertinente uma falta de consenso em relação aos critérios diagnósticos de desnutrição, inexistindo um padrão-ouro $(63,69-71)$.

Além do mais, aspectos peculiares relacionados ao envelhecimento obrigam a avaliação mais profunda, com análise de fatores de risco $(67,70)$.

A saúde bucal deve ser observada, pois a perda dos dentes e outras afecções da cavidade oral causando dor e dificuldade para mastigar e deglutir estão associadas com desnutrição $(65,72)$. Esta avaliação se reveste de importância, pois medidas preventivas e procedimentos odontológicos simples podem resolver o problema (72), além do que a habilidade de mastigar comida eficientemente, não influencia a capacidade de digestão com as dietas modernas (73).

Outro aspecto relevante na avaliação do idoso compreende verificação do nível funcional através da quantificação das atividades da vida diária (básicas e instrumentais), permitindo a classificação funcional: a) I, fisicamente incapaz ou dependente; b) II, fisicamente frágil; c) III, fisicamente independente; d) IV, fisicamente apto/ativo; e) V, atleta $(74,75)$. Dependência para comer encontra-se relacionada com aumento da mortalidade (67). O nível de independência funcional é um forte preditor de complicações (76).

A antropometria de idosos apresenta peculiaridades, como: a) possibilidade de estimar o peso utilizando fórmulas que aplicam variáveis antropométricas, quando o mesmo não pode ser medido: peso (homens $)=(0,98 \times \mathrm{CP})+(1,16 \times$ altura do joelho $)+$ $(1,73 \times \mathrm{CB})+(0,37 \times$ prega subescapular $)-81,69$; peso (mulheres $)=(1,27 \times \mathrm{CP})+(0,87 \times$ altura do joelho $)+(0,98 \times \mathrm{CB})+(0,4 \times$ prega subescapular $)-$ 62,35 ; b) estimar a altura utilizando a medida da altura do joelho aplicada a fórmulas e a altura em posição sentada; c) a circunferência da panturrilha (CP) é considerada a medida mais sensível de massa muscular no idoso, sendo superior à circunferência do braço (CB) $(5,13)$. 
A Avaliação Subjetiva Global (ASG) tem sido utilizada na população geriátrica, sendo considerada um instrumento útil na avaliação do estado nutricional em idosos $(63,69)$.

Vários instrumentos têm sido desenvolvidos em uma tentativa de identificar os idosos desnutridos ou em risco nutricional.

The Nutrition Screening Initiative (NSI) é um questionário de dez perguntas auto-aplicável, desenvolvido para ser utilizado na atenção primária à saúde com o objetivo de despertar a consciência sobre problemas nutricionais, porém tem se mostrado de eficiência limitada, não sendo capaz de predizer mortalidade $(62,70)$.

A Miniavaliação Nutricional (MAN) foi desenvolvida para avaliar o risco de desnutrição em idosos e identificar aqueles que possam se beneficiar de intervenção precoce (77). A versão original é composta por 18 itens que englobam antropometria, avaliação dietética, avaliação clínica global e autopercepção de saúde e estado nutricional (quadro 1), podendo ser utilizado tanto para triagem como para avaliação, e deve ser aplicado por profissional de saúde $(62,69)$. Vários estudos têm validado a MAN, mostrando que é capaz de predizer o aumento do tempo de internação, a alta para asilos e mortalidade $(62,69,71,78)$.

Porém, a maioria dos autores considera como padrão-ouro as medidas antropométricas e exames laboratoriais (linfócitos totais, albumina, colesterol sérico, hemoglobina e transferrina) $(67,69,72,79,80)$.

Quadro 1. Miniavaliação Nutricional.

\section{TRIAGEM}

A. Nos últimos meses, houve diminuição da ingestão alimentar devido à perda de apetite, problemas digestivos ou dificuldade para mastigar e deglutir? (0) diminuição severa da ingestão; (1) diminuição moderada da ingestão; (2) sem diminuição da ingestão

B. Perda de peso nos últimos meses: (0) superior a três quilos; (1) não sabe informar; (2) entre um e três quilos; (3) sem perda de peso

C. Mobilidade: (0) restrito ao leito ou à cadeira de rodas; (1) deambula, mas não é capaz de sair de casa; (2) normal

D. Passou por algum estresse psicológico ou doença aguda nos últimos três meses? (0) sim; (2) não

E. Problemas neuropsicológicos: (0) demência ou depressão graves; (1) demência leve; (2) sem problemas psicológicos

F. Índice de massa corporal: (0) IMC < 19; (1) $19 \leq \mathrm{IMC}<21$; (2) $21 \leq \mathrm{IMC}<23$; (3) IMC $\geq 23$

\section{A. ESCORE TRIAGEM (subtotal, máximo 14 pontos)}

SOMA DOS PONTOS

(0) normal (12 pontos ou mais); (1) possibilidade de desnutrição (11 pontos ou menos)

AVALIAÇÃO GLOBAL

G. O paciente vive em sua própria casa (não em casa geriátrica ou hospital) (0) não; (1) sim

H. Utiliza mais de três medicamentos diferentes por dia? (0) sim; (1) não

I. Lesões de pele ou escaras? (0) sim; (1) não

J. Quantas refeiçōes faz por dia? (0) uma refeição; (1) duas refeições; (2) três refeiçōes

K. O paciente consome:

1. pelo menos uma porção diária de leite ou derivados (queijo, iogurte)?

() $0 . \operatorname{sim} ;$ ( ) 1. não

2. duas ou mais porções semanais de legumes ou ovos:

() $0 . \operatorname{sim} ;$ () 1 . não

3. carnes, peixes ou aves todos os dias:

() $0 . \operatorname{sim} ;$ ( ) 1. não

\section{PONTUAÇÃO:}

$0,0=$ nenhuma ou uma resposta "sim"

$0,5=$ duas respostas "sim"

$1,0=$ três respostas "sim"

L. O paciente consome duas ou mais porções diárias de frutas ou vegetais: (0) não; (1) sim

M. Quantos copos de líquidos (água, suco, café, chá, leite) o paciente consome por dia? 0,0 = menos de três; 0,5 = três a cinco copos; $1,0=$ mais de cinco copos

N. Modo de se alimentar: (0) não é capaz de se alimentar sozinho; (1) alimenta-se sozinho, porém com dificuldade; (2) alimenta-se sozinho sem dificuldade

O. O paciente acredita ter algum problema nutricional? (0) acredita estar desnutrido; (1) não sabe dizer; (2) acredita não ter problema nutricional

P. Em comparação com as pessoas da mesma idade, como o paciente considera a sua própria saúde? 0,0 = não muito boa;

$0,5=$ não sabe informar; $1,0=$ boa; $2,0=$ melhor

$Q$. Circunferência do braço $(C B)$ em $\mathrm{cm}$ :

$0,0=\mathrm{CB}<21 ; 0,5=21 \leq \mathrm{CB} \leq 22 ; 1,0=\mathrm{CB}>22$

R. Circunferência da panturrilha $(C P)$ em $\mathrm{cm}$ :

$0=\mathrm{CP}<31 ; 1=\mathrm{CP} \geq 31$

B. ESCORE AVALIAÇÃO GLOBAL (máximo 16 pontos)

C. ESCORE TOTAL (máximo 30 pontos)

SOMA DE A + B.

ESCORE DE INDICAÇÃO DE DESNUTRIÇÃO

Bem nutrido: MAN $1>23,5$ pontos

Em risco de desnutrição: $17 \leq$ MAN $2 \leq 23,5$ pontos

Desnutrido: MAN $3<17$ pontos

Fonte: referência 77 . 


\section{Métodos Não Convencionais}

Com a evolução dos conhecimentos sobre composição corporal, a tentativa de organização dos vários métodos de pesquisa desenvolvidos na área resultou na criação de um modelo em cinco níveis: I - Atômico; II Molecular; III - Celular; IV - Sistema tecidual; V Todo o corpo (5).

Os métodos não-convencionais são citados a seguir $(9,18)$ :

Provas funcionais: a) para avaliar função muscular: têm sido usadas em pesquisas com resultados promissores $(81)$; b) a imunidade celular: através de testes de hipersensibilidade cutânea retardada;

Densitometria computadorizada, analisando as diferentes densidades dos compartimentos corpóreos;

Hidrodensitometria ou pesagem hidrostática: pesar o indivíduo embaixo d'água;

Isótopos marcados pela medição da água corporal total;

Análise da ativação de nêutrons in vivo: através do bombardeamento de nêutrons;

Ressonância magnética: pela análise de imagens de alta resolução.

$\mathrm{Na}$ tabela 4, são apresentadas as bases técnicas que fundamentam cada um deles, e, na tabela 5 , as principais vantagens e desvantagens dos métodos nãoconvencionais.

\section{SITUAÇĀO NUTRICIONAL DA POPULAÇĀO BRASILEIRA}

No Brasil, ao contrário do que se observa nos Estados Unidos e em alguns países europeus, a realização de inquéritos populacionais de representatividade nacional não ocorre de forma sistemática (82), de forma que os dados disponíveis referem-se aos resultados de duas pesquisas com representatividade nacional sobre o perfil nutricional da população brasileira (83-85):

Estudo Nacional da Despesa Familiar (ENDEF), realizado em 1974-1975 pelo IBGE com assessoria da FAO, com o objetivo de caracterizar as condições de saúde, o estado nutricional e a estrutura socioeconômica das famílias. A amostra atingiu 55.000 famílias;

Pesquisa Nacional sobre Saúde e Nutrição (PNSN), realizada em 1989 pelo IBGE conveniado com o INAN e o IPEA, com os mesmos objetivos do ENDEF, atingindo 14.000 famílias.

A PNSN foi desenhada para ser representativa de toda a população brasileira. Entretanto, ocorreu a limitação de não ser representativa de alguns grupos com risco expressivo de desnutrição: internos em instituições, habitantes do Norte rural, os índios e a população de rua (85).

Mais recentemente, realizou-se a Pesquisa sobre Padrão de Vida (PPV), realizada em 1997 pelo IBGE, porém somente nas regiões Nordeste e Sudeste (86).

Vários autores $(33,37,83-85)$ fizeram comparações entre o estado nutricional de adultos avaliado pelos ENDEF e PNSN.

Coitinho e cols. (83) consideraram adultos indivíduos com 18 anos ou mais. O critério utilizado foi o índice de massa corporal (IMC) com os seguintes pontos de corte: a) baixo peso, IMC $<20,0$; b) normal, IMC de 20,0 a 24,99; c) sobrepeso, IMC de 25,0 a 29,99 ; d) obesidade, IMC $\geq 30,0$. Nas amostras, encontraram $15,9 \%$ de baixo peso, distribuído de forma semelhante para os dois sexos: $15,4 \%$ para homens e $16,5 \%$ para mulheres. O problema afetou principalmente idosos com renda domiciliar per capita menor que meio salário mínimo, atingindo mais de $25 \%$, em comparação com cerca de $10 \%$ de idosos, cuja renda excedeu dois salários mínimos per capita. A maior prevalência de baixo peso foi encontrada no Nordeste com $20 \%$ e a menor, na região Sul com $10 \%$.

Em outra parte da população estudada (83), $24,6 \%$ apresentaram sobrepeso e $8,3 \%$ obesidade. O excesso de peso afetou proporcionalmente mais mulheres $(38 \%)$ que homens (27\%). Em geral, observouse que, quanto maior a renda, maior a prevalência de graus variados de excesso de peso. Contudo, este problema se mostrou também grave entre as pessoas de baixa renda, com prevalência de $16 \%$ para homens e de $30 \%$ para mulheres. Em todas as regiões o problema de excesso de peso foi considerado grave. A situação mais crítica foi na região Sul, com $34 \%$ em homens e $43 \%$ em mulheres. Neste estudo, foi observado que a situação nutricional de adultos mudou muito nos 15 anos entre uma pesquisa e outra (83), com redução de $36 \%$ na prevalência de baixo peso e o grande aumento da prevalência de excesso de peso: $100 \%$ de aumento para homens e $70 \%$ de aumento para mulheres, com redução do número de indivíduos antropometricamente normais.

Monteiro e cols. (34) consideraram adultos indivíduos com idades entre 25 e 64 anos. Na falta de critério universalmente aceito, adotaram como distribuição de referência para o IMC a distribuição encontrada na população americana entre 20 a 29 anos, estimada pela pesquisa denominada National Health and Nutrition Survey II 1976-1980 (NHANES II) (34). Consideraram como tendo magreza os indivíduos que apresentassem valores de IMC inferiores ao per- 
Tabela 4. Bases técnicas dos principais métodos não-convencionais.

Método Não-convencional Bases Técnicas

Densitometria computadorizada

Hidrodensitometria ou pesagem hidrostática

Isótopos marcados

Estudo de componentes nutricionais específicos

Análise da ativação de nêutrons in vivo

\section{Ressonância magnética (RM)}

Testes funcionais
Princípio: os compartimentos corpóreos (massa magra, gordura e osso) apresentam diferentes valores quanto à sua densidade.

Medição: por emissão de fóton de energia.

Resultados: fornece dados em kg quanto aos compartimentos de massa magra, massa gorda e óssea, a partir da medida do corpo inteiro.

Princípio: dois compartimentos corpóreos apresentam densidades físicas conhecidas e constantes, sendo a da gordura mais estável do que a da massa magra. Este é um método de referência e assume a densidade de gordura $0,9 \mathrm{~g} / \mathrm{cm}^{3}$ e da massa magra de $1,1 \mathrm{~g} / \mathrm{cm}^{3}$.

Medição: pesagem do indivíduo embaixo d'água.

Resultados: utilizando-se os valores de densidade de cada um dos compartimentos, o valor médio do peso do indivíduo sob a água e alguns cálculos matemáticos, estima-se a fração do peso corporal representada pela gordura e pela massa magra.

Princípios: os compartimentos corpóreos apresentam uma relação relativamente estável com a água corporal total. A partir da diluição isotópica, pode-se medir a água corporal total e estimar a massa magra e gorda do indivíduo.

Medição; água marcada com trítio, deutério ou 018.

Resultados: mensuração dos elementos marcados. Cálculos matemáticos inferiram os resultados do compartimento da massa magra e gorda.

Princípios: a desnutrição resulta em alterações nos valores de vitaminas e minerais em seus respectivos "locais de reserva".

Medição: depende do elemento em questão.

Exemplo: Estudo do Cálcio Corpóreo: mensuração da reserva e/ou turnover do cálcio ósseo, das perdas urinárias, dos valores séricos, de outros indicadores de seu metabolismo (por ex.: paratormônio e vitamina D).

Resultados: valores do elemento analisado segundo os diferentes órgãos e/ou locais de reserva e outros indicadores que direta ou indiretamente refletem seu status corpóreo.

Princípio: medem a composição corporal total a partir da contagem dos elementos ativados pelo "bombardeamento" de nêutrons.

Medição: após exposição à radiação, as células tornam-se e passiveis de serem contadas por detetores de alta resolução.

Resultados: fornece dados de todos os compartimentos corpóreos, massa magra celular corporal, gordura, massa magra, massa muscular esquelética e volumes hídricos, intra e extracelular.

Princípio: a partir da análise de imagens de alta resolução, é possivel mensurar cada um dos compartimentos. Mostra a representação dos componentes corpóreos em nível tecidual.

Medição: os "cortes" corpóreos feitos pelo campo magnético emitido pelo equipamento de RM são transformados em imagens que permitem a quantificação corporal total ou regional.

Resultados: fornece dados quanto aos componentes da composição corpórea em nível tecidual, incluindo-se a musculatura esquelética, a massa gorda, as vísceras e o cérebro.

Princípio: a desnutrição resulta em perdas importantes da função muscular. Medição: por estimulação do músculo adutor da coxa e/ou pela capacidade de expansão do músculo respiratório.

Resultados: razão entre as freqüências do músculo contraído/relaxado (taxa de relaxamento muscular).

Relação entre pico da expansão do músculo respiratório na inspiração e expiração.

Fonte: referência 9. 
Tabela 5. Principais vantagens e desvantagens dos métodos não-convencionais.

\begin{tabular}{|c|c|}
\hline Método Não-convencional & Vantagens e Desvantagens \\
\hline Densitometria computadorizada & $\begin{array}{l}\text { Vantagens } \\
\text { - É considerado um método gold standard frente aos demais } \\
\text { - É aplicável mesmo nas situações de doenças } \\
\text { Desvantagens } \\
\text { - Equipamento muito caro } \\
\text { - Elevada dificuldade técnica } \\
\text { - Limitado nos grandes obesos } \\
\text { Hidrodensitometria ou pesagem hidrostática } \\
\text { Vantagens } \\
\text { - Método de referência desde } 1950 \\
\text { - Excelente aceitação no meio científico, ferramenta para pesquisa } \\
\text { - Aparelhagem relativamente pouco onerosa } \\
\text { Desvantagens } \\
\text { - Mudanças na composição dos fluídos corpóreos interferem negativamente } \\
\text { nos cálculos de massa magra } \\
\text { - Não é indicado para a população enferma } \\
\text { - Não é confiável em indivíduos que não suportam ficar embaixo d'água por } \\
\text { longos períodos } \\
\text { - Exige um técnico treinado para conduzir o estudo }\end{array}$ \\
\hline Isótopos marcados & $\begin{array}{l}\text { Vantagens } \\
\text { - Precisão na análise do elemento marcado (fluídos e íons) } \\
\text { Desvantagens } \\
\text { - Limitações frente a situações de doença } \\
\text { - Isótopos são compostos caros para o nosso meio }\end{array}$ \\
\hline $\begin{array}{l}\text { Estudo de componentes } \\
\text { nutricionais específicos }\end{array}$ & $\begin{array}{l}\text { Vantagens } \\
\text { - Adequado quando inserido em uma "linha de pesquisa" } \\
\text { Desvantagens } \\
\text { - Oneroso por envolver diversas análises } \\
\text { - Finalização do estudo relativamente lenta }\end{array}$ \\
\hline Análise da ativação de nêutrons & $\begin{array}{l}\text { Vantagens } \\
\text { - Método de referência } \\
\text { - Adequado para pesquisas } \\
\text { Desvantagens } \\
\text { - Oneroso } \\
\text { - Elevada dose de radiação }\end{array}$ \\
\hline Ressonância magnética & $\begin{array}{l}\text { Vantagens } \\
\text { - Vem sendo cada vez mais estudada como um método de referência para } \\
\text { a avaliação corpórea } \\
\text { - Erro técnico tende a ser pequeno } \\
\text { - Abre possibilidades para estudos em crianças e em grávidas } \\
\text { Desvantagens } \\
\text { - Limitado para os enfermos com problemas de claustrofobia, os obesos mór- } \\
\text { bidos ou, mesmo, no extremo do déficit nutricional e em indivíduos com } \\
\text { implantes metálicos } \\
\text { - Aplicação clínica ainda limitada }\end{array}$ \\
\hline Testes funcionais & $\begin{array}{l}\text { Vantagens } \\
\text { - Relativamente barato } \\
\text { - Dificuldade técnica relativamente elevada (teste de função pulmonar) } \\
\text { Desvantagens } \\
\text { - Influenciado por medicação, doenças musculares intrínsecas, hipóxia, } \\
\text { hipercapnia, motivação do enfermo }\end{array}$ \\
\hline
\end{tabular}

Fonte: referência 9. 
centil 5 da referência (homens com IMC $<19,4$; mulheres com IMC $<17,9)$. Encontraram prevalência de $10,9 \%$ de magreza em homens na zona rural e $6,8 \%$ na zona urbana e em $5,0 \%$ das mulheres na zona rural e $2,6 \%$ na zona urbana. Estudo comparativo entre os inquéritos de 1974 e de 1989 revelou declínio pronunciado e generalizado na proporção de indivíduos com baixo índice de massa corporal (34).

Em outro estudo, Monteiro e cols. (33) realizaram um estudo comparativo entre o ENDEF e PNSN, considerando desnutrição e obesidade. Adultos foram considerados os indivíduos na faixa etária entre 25 e 64 anos. O IMC foi o critério utilizado para classificação, sendo considerados desnutridos aqueles que apresentassem IMC $<18,5$ e obesos IMC $>30,0$. Os autores observaram que a prevalência de adultos desnutridos reduziu substancialmente, mas a de obesidade dobrou. Ocorreu inversão da razão entre desnutrição e obesidade: em 1974, a desnutrição excedia a obesidade em uma vez e meia, enquanto em 1989 a obesidade excedeu a desnutrição em mais de duas vezes. Este fato mostrou que, no Brasil, o problema da escassez tem sido rapidamente substituído pelo problema do excesso alimentar, que ocorreu em todos os estratos econômicos com aumento proporcional mais elevado nas famílias de baixa renda. A este fenômeno denomina-se transição nutricional (33).

Segundo dados mais recentes obtidos pela PPV, a prevalência de obesidade na população masculina aumentou nas duas regiões estudadas, sendo o aumento bem maior na região Nordeste que na Sudeste (86). Um achado peculiar desta pesquisa foi o declínio da obesidade observado entre as mulheres da região $\mathrm{Su}$ deste do maior quartil de renda (82). A queda foi de $13,2 \% \mathrm{em} 1999$ para 8,2\% em 1997, fato ainda não observado em nenhum país em desenvolvimento (86).

Conforme a World Health Organization, o crescente aumento da prevalência da obesidade se caracteriza como uma pandemia global, constituindo-se em grave problema para o âmbito da Saúde Pública (6). Dados relacionados com sobrepeso e obesidade demonstram que um terço da população adulta em vários países apresenta este problema (87).

Outro aspecto importante levantado pelos inquéritos populacionais, foi a diferença entre peso e altura dos brasileiros, observada nas diferentes regiões $(88)$.

As tabelas de peso e altura mais atuais foram elaboradas a partir dos dados coletados pela Pesquisa de Padrões de Vida, PPV (89).

A altura é um dos indicadores que permite avaliar o estado nutricional da população em suas diversas faixas etárias (89). Os diferenciais da altura ocorrem em situações variadas de condições de vida. Assim sendo, estatura mais elevada significa, entre outros fatores, alimentação rica em proteínas e sais minerais e, de outra parte, condições sanitárias mais adequadas (11). A PPV (89) demonstra a altura mediana na faixa etária de um a 26 anos e o IMC a partir de 20 anos. Estes dados, comparados com a PNSN $(83,90)$, revelam um crescimento de dois centímetros em todas as idades. A região Sudeste apresentou as alturas medianas superiores em todas as idades. A altura $8 \mathrm{~cm}$ mais elevada de homens na zona urbana comparados aos da zona rural foi observada (89).

Nas tabelas de altura de um a 26 anos (90), com dados obtidos da PNSN, é possível citar como exemplo que a mediana das alturas de homens de 25 anos na região Sul é de $171,6 \mathrm{~cm}$, na região Nordeste é de $167,9 \mathrm{~cm}$ e na região Norte é de $165,0 \mathrm{~cm}$.

A estatura reduzida e o baixo peso corporal seriam indicativos de ocorrência de desnutrição nos períodos iniciais do ciclo vital (88). Mais importante ainda, um dos aspectos mais comprometedores da desnutrição se refere à diminuição da capacidade mental (88).

Anjos (29) relata que os dados da PNSN confirmam o fato de que, mesmo no segmento da população de melhores condições de renda, a mediana da estatura dos adultos brasileiros não alcança a estatura de populações do Primeiro Mundo.

Entretanto, apesar das diferenças regionais, Monteiro e cols. (35) constataram tendência positiva secular de crescimento. A referida tendência é contínua desde a década de 50 do século $\mathrm{XX}$, mas tem se acelerado mais recentemente; esteve presente em todas as regiões do país e em todos os estratos da população. Ressaltaram, porém, a larga distância que separa o padrão de crescimento observado nas regiões Norte e Nordeste, no terço mais pobre da população, do padrão esperado quando são apropriadas as condições de vida.

\section{CONCLUSŌES}

A avaliação do estado nutricional, de grande importância na prática clínica, não dispõe de padrão-ouro para diagnóstico das desordens nutricionais. $\mathrm{O}$ melhor método depende dos objetivos da avaliação. Desta forma, em estudos populacionais, a OMS preconiza a utilização do IMC. Já em pacientes hospitalizados com a possibilidade de realizar exames laboratoriais, a utilização de índices múltiplos permite detectar desnutrição subclínica. Com a finalidade de pesquisa, os métodos não-convencionais desempenham papel 
importante, mas têm custo elevado para realização rotineira. A ASG é um bom instrumento para ser utilizado em triagem. O idoso apresenta aspectos peculiares que obrigam a realização de avaliação mais complexa com análise de fatores de risco, como determinação do nível funcional, avaliação da saúde bucal e investigação sobre depressão. Vários instrumentos foram desenvolvidos para avaliar o estado nutricional de idosos, dentre eles, a Miniavaliação Nutricional (MAN) merece destaque, pois engloba antropometria, avaliação dietética, avaliação clínica global e autopercepção de saúde e estado nutricional.

Os inquéritos populacionais realizados no Brasil encontraram uma prevalência de baixo peso em torno de $15,0 \%$, distribuído de forma semelhante para os dois sexos. O problema afetou principalmente idosos com renda domiciliar per capita menor que meio salário mínimo, atingindo mais de $25 \%$, em comparação com cerca de $10 \%$ de idosos cuja renda excedeu dois salários mínimos per capita. A prevalência de sobrepeso foi de aproximadamente $25,0 \%$ e de obesidade foi de $8,3 \%$, demonstrando que o problema da escassez tem sido rapidamente substituído pelo excesso alimentar, fenômeno denominado transição nutricional. Segundo a World Health Organization, o crescente aumento da prevalência da obesidade se caracteriza como uma pandemia global, também observada no Brasil.

\section{REFERÊNCIAS}

1. DeHoog S. Avaliação do Estado Nutricional. In: Mahan KL, Escott-Stump S. Krause: Alimentos, nutriçāo \& dietoterapia. 9a. ed, São Paulo: Roca, 1998. p.371-96.

2. Jeejeebhoy KN, Detsky AS, Baker JP. Assessment of Nutritional Status. JPEN 1990;14/5:193S-6S.

3. McWhirter JP, Pennington CR. Incidence and recognition of malnutrition in hospital. Br Med J 1994;308:945-8.

4. OMS, Organização Mundial da Saúde. Manejo da desnutrição grave: um manual para profissionais de saúde de nível superior e suas equipes auxiliares. Genebra, 2000.

5. WHO, World Health Organization. Physical status: The use and interpretation of anthropometry. Report of a WHO expert committee. Geneva, 1995.

6. WHO, World Health Organization. Obesity: Preventing and managing the global epidemic. Report of a WHO consultation on obesity. Geneva, 1998.

7. Smith LC, Mullen JL. Nutritional assessment and indications for nutritional support. Surg Clin North Am $1991 ; 71 / 3: 449-57$.

8. Jeejeebhoy KN. Nutritional assessment. Clin Nutr 1998;27/2:347-69.
9. Baxter YC, Waitzberg DL, Peres G. Métodos não-convencionais; estudo dietético e medida da qualidade de vida. In: Waitzberg DL. Nutrição oral, enteral e parenteral na prática clínica. $3^{a}$. ed. São Paulo: Atheneu, 2000. p.305-19.

10. Albert MB, Callaway CW. Clinical nutrition for the house officer. Baltimore: Williams \& Wilkins, 1992.

11. Stallings VA, Hark L. Nutrition assessment in medical practice. In: Morrison G, Hark L. Medical nutrition and disease. Cambridge: Blackwell, 1996. p.3-30.

12. Silva MCGB. Avaliação Subjetiva Global. In: Waitzberg $D L$. Nutrição oral, enteral e parenteral na prática clínica. $3^{a}$ ed. São Paulo: Atheneu, 2000. p.241-54.

13. Waitzberg DL, Ferrini MT. Exame Físico e Antropometria. In: Waitzberg DL. Nutrição oral, enteral e parenteral na prática clínica. $3^{a}$ ed. São Paulo: Atheneu, 2000. p.25578.

14. Lohman TG, Roche AF, Martorell R. Anthropometric standardization reference manual. Champaign: Human Kinetics Books, 1988.

15. Willett W. Nutritional epidemiology. $2^{\text {th }}$ edition. Oxford: Oxford University Press, 1998.

16. Heyward VH, Stolarczyk LM. Avaliação da composição corporal aplicada. 1a. ed. São Paulo: Manole, 2000.

17. Bottoni A, Oliveira GPC, Ferrini MT, Waitzberg DL. Avaliação nutricional: exames laboratoriais. In: Waitzberg DL, ed. Nutrição oral, enteral e parenteral na prática clínica. 3a. ed. São Paulo: Atheneu, 2000. p.279-94.

18. Charney P. Nutrition assessment in the 1990s: Where are we now? Nutr Clin Pract 1995;10:131-9.

19. Waitzberg DL, Rodrigues JG, Gama AH, Faintuch J. Desnutrição. In: Waitzberg DL, ed. Nutrição Oral, enteral e parenteral na prática clínica. $2{ }^{a}$ ed. São Paulo: Atheneu, 1995. p.153-61.

20. Coppini LZ, Waitzberg DL. Impedância bioelétrica. In: Waitzberg DL, ed. Nutrição oral, enteral e parenteral na prática clínica. 3a. ed., São Paulo: Atheneu, 2000. p.295-304.

21. Correia MIT. Avaliação nutricional subjetiva. Rev Bras Nutr Clin 1998;13:68-73.

22. Haken V. Interações entre drogas e nutrientes. In: Mahan KL, Escott-Stump S, ed. Krause: Alimentos, nutrição \& dietoterapia. 9a ed. São Paulo: Roca, 1998. p.397-413.

23. Detsky AS, McLaughlin JR, Baker JP, Johnston N, Whittaker S, Mendelson RA, et al. What is subjective global assessment of nutritional status? JPEN 1987;11:8-13.

24. Coppini LZ, Waitzberg DL, Ferrini MT, Silva MIT, GamaRodrigues J, Ciosak SL. Comparação da avaliação nutricional subjetiva global $x$ avaliação objetiva. Rev Assoc Med Bras 1995;41:6-10.

25. Silva MCGB. Avaliação subjetiva global. In: Waitzberg $D L$, ed. Nutrição oral, enteral e parenteral na prática clínica. 3a. ed. Atheneu: São Paulo, 2000. p.241-54.

26. Johnson RC, McClearn, Yuen S, Nagoshi CT, Ahern FM, Cole RE. Galton's data a century later. Am Psychol 1985;40:875-92. 
27. Shils ME, Olson JA, Moshe S. Nutrition in health and disease. $8^{\text {th }}$ ed. Baltimore: Williams \& Wilkins, 1994.

28. Gibson RS. Nutritional assessment: A laboratory manual. Oxford: Oxford University Press, 1993.

29. Anjos LA. Índice de massa corporal (massa corporal $x$ estatura $^{2}$ ) como indicador do estado nutricional de adultos: revisão da literatura. Rev Saude Publica 1992;26:431-6.

30. Waitzberg DL. Avaliação nutricional de pacientes no pré e pós-operatório de cirurgia de aparelho digestivo. Método antropométrico e laboratorial. Tese de Mestrado. Universidade de São Paulo, 1981.

31. Kelly IE, Tessier S, Cahill A, Morris SE, Crumley A, Mclaughlin D, et al. Still hungry in hospital: identifying malnutrition in acute hospital admissions. QJM 2000;93/2:93-8.

32. Coitinho DC, Leão MM, Recine E, Sichieri R. Condiçōes nutricionais da população brasileira: Adultos e idosos. Pesquisa nacional sobre saúde e nutrição. Brasília: INAN, Instituto Nacional de Alimentação e Nutrição, 1991.

33. Monteiro CA, Mondini L, Souza ALM, Popkin BM. Da desnutrição para a obesidade: a transição nutricional no Brasil. In: Monteiro CA, ed. Velhos e novos males da saúde no Brasil: A evolução do país e de suas doenças. São Paulo: HUCITEC, 1995. p.247-55.

34. Monteiro CA, Souza ALM, Mondini L. Evolução da desnutrição entre adultos. In: Monteiro CA, ed. Velhos e novos males da saúde no Brasil: A evoluçāo do país e de suas doenças. São Paulo: HUCITEC, 1995. p. 115-25.

35. Monteiro CA, Benicio MHD, Gouveia NC. Evolução da altura dos brasileiros. In: Monteiro CA, ed. Velhos e novos males da saúde no Brasil: A evolução do país e de suas doenças. São Paulo: HUCITEC, 1995. p.12740.

36. Garrow JS, Webster J. Quetelet's index $\left(W / H^{2}\right)$ as a measure of fatness. Int J Obes 1985;9:147-53.

37. Smalley KJ, Knerr NA, Kendrick ZV, Colliver JA, Owen OE. Reassessment of body mass indices. Am J Clin Nutr 1990;52:405-8.

38. Acuña K, Portela M, Costa-Matos A, Bora L, Teles MR, Waitzberg DL, et al. Nutritional Assessment of Adult Patients Admitted to a Hospital of the Amazon Region. Nutrición Hospitalaria 2003;18:138-43.

39. Waitzberg DL, Caiffa WT, Correia MITD. Hospital malnutrition: the Brazilian national survey (IBRANUTRI): a study of 4000 patients. Nutrition 2001;17:573-80.

40. Gianino S, Robert E, John S. Nutritional assessment of the patient in the intensive care unit. Crit Care Nurs North Am 1993;5/1:1-16.

41. Jelliffe DB. The assessment of nutritional status of the community. Geneve: World Health Organization, 1966.

42. Frisancho AR. New norms of upper limb fat and muscle are for assessment of nutritional status. Am J Clin Nutr 1981;34:2540-5.

43. Thuluvath PJ, Triger DR. How Valid are Our Reference Standards of Nutrition? Nutrition 1995;11:731-3.

44. Weinsier RL, Hunker EM, Krumdiek CL, Butterworth Jr CE.
Hospital malnutrition: a prospective evaluation of general medical patients during the course of hospitalization. Am J Clin Nutr 1979;32:418-26.

45. Seltzer MH, Bastidas JA, Cooper DM, Engler P, Slocum B, Fletcher S. Instant Nutritional Assessment. JPEN 1979;3:157-9.

46. FELANPE, Federação Latino-Americana de Nutrição Parenteral e Enteral. Terapia nutricional total: Livro de trabalho do instrutor, 1997.

47. Young GA, Chem C, Hill GL. Assessment of protein-calorie malnutrition in surgical patients from plasma proteins and anthropometric measurements. Am J Clin Nutr 1978;31:429-35.

48. Harvey KB, Moldawer LL, Bistrian BR, Blackburn GL. Biological measures for the formulation of a hospital prognostic index. Am J Clin Nutr 1981;34:2013-22.

49. Klein S, Kinney J, Jeejeebhoy K, Alpers D, Hellerstein M, Murray $M$, et al. Nutrition support in clinical practice: Review of published data and recommendations for future research directions. JPEN 1997;21:133-56.

50. Bistrian BR, Blackburn GL, Hallowell E, Heddle R. Protein status of general surgical patients. JAMA 1974;230:85860.

51. Bistrian BR, Blackburn GL, Bistrian BR, Blackburn GL, Itale $J$, Cochran D, et al. Prevalence of malnutrition in general medical patients. JAMA 1976;235:1567-70.

52. Bistrian BR. Nutritional assessment and therapy of proteincalorie in the hospital. J Am Diet Assoc 1977;71:393-7.

53. Bistrian BR. Anthropometric norms used in assessment of hospitalized patients. Am J Clin Nutr 1980;33:221 1-4.

54. Blackburn GL, Bistrian BR, Maini BS, Schlamm HT, Smith MF. Nutritional and metabolic assessment of the hospitalized patient. JPEN 1977;1:11-22.

55. Mullen JL, Gertner MH, Buzby GP, Goodhart GL, Rosato EF. Implications of malnutrition in the surgical patient. Arch Surg 1979;114:121-5.

56. Willard MD, Gilsdorf RB, Price RA. Protein-calorie malnutrition in a community hospital. JAMA 1980;243:1720-2.

57. Detsky AS, Baker JP, Mendelson RA, Wolman SL, Wesson $\mathrm{DE}$, Jeejeebhoy KN. Evaluating the accuracy of nutritional assessment techniques applied to hospitalized patients: methodology and comparisons. JPEN 1984;8:153-9.

58. Buzby GP, Mullen JL, Matheus DC, Hobbs CL, Rosato EF. Prognostic Nutritional Index in Gastrointestinal Surgery. Am J Surg 1980;139:160-7.

59. Hoffman D, Heymsfield SB, Waitzberg DL. Composição Corpórea. In: Waitzberg DL, ed. Nutrição oral, enteral e parenteral na prática clínica. $3^{\text {da }}$. ed. São Paulo: Atheneu, 2000. p.225-39.

60. Acuña K. Avaliação do estado nutricional de adultos internados em hospital público do Acre. Dissertação de Mestrado. Universidade Federal da Bahia, 2002.

61. Naber THJ, Schermer T, Bree A, Nusteling K, Eggink L, Kruimel JW, et al. Prevalence of malnutrition in nonsurgical hospitalized patients and its association with disease complications. Am J Clin Nutr 1997;66:1232-9.

62. Beck AM, Ovesen L, Osler M. The mini nutritional assessment (MNA) and the "determine your nutritional health" 
checklist (NSI checklist) as predictor of morbidity and mortality in an elderly Danish population. $\mathbf{B r} \mathbf{J}$ Nutr 1999;81:31-6.

63. Sacks GS, Dearman K, Replogle WH, Cora VL, Meeks M, Canada T. Use of subjective global assessment to identify nutrition-associated complications and death in geriatric long-term care facility residents. Am Col Nutr 2000; 19:570-7.

64. Alarcón T, Barcena A, González-Montalvo Jl, Peñalosa C. Factors predictive of outcome on admission to an acute geriatric ward. Age and Ageing 1999;28:429-32.

65. Jensen GL, Friedmann JM, Coleman CD, SmiciklasWright $\mathrm{H}$. Screening for hospitalization and nutritional risks among community-dwelling older persons. Am J Clin Nutr 2001;74:201-5.

66. Roubenoff R. The Pathophysiology of Wasting in the Elderly. J Nutr 1999;129:256S-9S.

67. Thomas DR, Ashmen W, Morley JE, Evans WJ. Nutritional management in long-term care: Development of a clinical guideline. J Gerontol Med Sci 2000;55A:M725M34.

68. Wilson MMG, Purushothaman R, Morley JE. Effect of liquid dietary supplements on energy intake in the elderIy. Am J Clin Nutr 2002;75:944-7.

69. Christensson I, Unossom M, Ek A-C. Evaluation of nutritional assessment techniques in elderly people admitted to municipal care. Eur J Clin Nutr 2002;56:810-8.

70. Azad N, Murphy J, Amos SS, Toppan J. Nutrition survey in an elderly population following admission to a tertiary care hospital. Can Med Assoc J 1999;161:511-5.

71. Thomas DR, Zdrowski CD, Wilson MM, Conright KC, Lewis C, Tariq S. Malnutrition in subacute care. Am J Clin Nutr 2002; $75: 308-13$

72. Mojon $\mathrm{P}$, Budtz-Jorgensen $\mathrm{E}$, Rapin $\mathrm{CH}$. Relationship between oral health and nutrition in very old people. Age and Aging 1999;28:463-8.

73. Walls AWG. Oral health and nutrition. Age and Ageing 1999;28:419-20.

74. Siegler E, Hark L. Older adults. In: Morrison G, Hark L, ed. Medical nutrition and disease. Blackwell: Cambridge, 1996. p. $143-55$.

75. Matsudo SMM. Avaliação do idoso: Física \& funcional. Londrina: Midiograf, 2000. p.125.

76. Sullivan DH, Walls RC, Lipschitz DA. Protein-energy undernutrition and the risk of mortality within $1 \mathrm{y}$ of hospital discharge in a select population of geriatric rehabilitation patients. Am J Clin Nutr 1991;53:599-605.

77. Guigoz Y, Vellas B, Garry PJ. Mini nutritional assessment: A practical assessment tool for grading the nutritional state of elderly patients. Facts and Research in Gerontology 1994;2:15-59.

78. Nes MCV, Herrmann FR, Gold G, Michel JP, Rizzoli R. Does the mini nutritional assessment predict hospitalization outcomes in older people? Age and Aging 2001;30:221-6.
79. Agarwal N, Acevedo F, Leigton LS, Cayten CG, Pitchumoni CS. Predictive ability of various nutritional variables for mortality in elderly people. Am J Clin Nutr 1988;48:1173-8.

80. Bohmer T, Mowé M. The association between atrophic glossitis and protein-calorie malnutrition in old age. Age and Aging 2000;29:47-50.

81. Waitzberg DL, Terra RM. Função muscular e sua relação com nutrição e desnutrição. In: Waitzberg DL, ed. Nutricão oral, enteral e parenteral na prática clínica. 3a. ed. São Paulo: Atheneu, 2000. p.321-5.

82. Kac G. Fatores determinantes da retenção de peso no pós-parto: uma revisão da literatura. Cad Saúde Pública 2001;17:453-66.

83. Coitinho DC, Leão MM, Recine E, Sichieri R. Condiçōes nutricionais da população brasileira: Adultos e idosos. Pesquisa nacional sobre saúde e nutrição. Brasília: INAN, Instituto Nacional de Alimentação e Nutrição, 1991.

84. Castro IRR. Vigilância alimentar e nutricional: Limitaçōes e interfaces com a rede de saúde. Rio de Janeiro: FIOCRUZ, 1995.

85. Bittencourt AS, Magalhães RF. Fome: um drama silencioso. In: Minayo MCS, ed. Os muitos Brasis: Saúde e população na década de $\mathbf{8 0}$. São Paulo: HUCITEC, 1995. p.269-89.

86. Monteiro CA, Conde WL. A tendência secular da obesidade segundo estratos sociais: Nordeste e Sudeste do Brasil, 1975-1989-1997. Arq Bras Endocrinol Metab 1999;43:186-94

87. Nucci LB, Duncan BB, Mengue SS, Brachtein L, Schmidt $\mathrm{MI}$, Fleck ET. Assessment of weight gain during pregnancy in general prenatal care services in Brazil. Cad Saúde Pública 2001;17:1367-74.

88. Arruda IKG, Arruda BKG. Nutrição e Desenvolvimento. Cad Saúde Pública 1992;10:392-7.

89. IBGE - Instituto Brasileiro de Geografia e Estatística. Pesquisa sobre padrōes de vida 1996-1997. Disponível no endereço eletrônico: atendimentoes@ibge.br. Acesso em 30 de julho de 2002.

90. INAN - Instituto Nacional de Alimentação e Nutrição. Pesquisa nacional sobre saúde e nutrição. Perfil de crescimento da população brasileira de 0 a 25 anos. Brasília, 1990.

Endereço para correspondência:

Kátia Acuña

Caixa Postal 152, Correio Central

69908-970 Rio Branco, AC

e.mail: katia.aravena@ac.gov.br 